\title{
Effect of permanent magnetic field on the properties of static water and germination of cucumber seeds
}

\author{
Olfa Cheikh ${ }^{1}$, Anis Elaoud ${ }^{1 *}$, Hamza Ben Amor ${ }^{1,2}$ and Mahmoud Hozayn ${ }^{3}$ \\ ${ }^{1}$ Laboratory of Environmental Science and Technologies, Higher Institute of Sciences and Technology of Environment, Carthage University, Tunisia \\ ${ }^{2}$ University of Carthage, National Institute of Agronomic, Tunisia \\ ${ }^{3}$ National Research Center, Egypt
}

Received 05 Jan 2018, Accepted 02 Feb 2018, Available online 10 Feb 2018, Vol.6 (Jan/Feb 2018 issue)

\begin{abstract}
Water scarcity and concentration of salts in soils are currently considered as threats to human life. The degradation of irrigation water quality is mainly due to overexploitation of natural resources, poor management and pollution. However, these factors limit the development of agriculture. Although the method of treating water by a magnetic field is a technique that has recently been introduced into different fields, including agriculture, it can be considered as a solution to reduce the salinity problems of irrigation water. On the other hand, magnetized water is the water exposed to magnetic rays which undergoes physical and chemical variations. The purpose of this study is to evaluate the effect of magnetic treatment the advantages of magnetically treated water on the rate of germination and the germinal faculty of cucumber seeds. In addition, experiments were performed with two magnetic devices: $A 1=0.5$ Tesla; A2 = 0.29 Tes/a As a result, the application of a magnetic field influenced the parameters of the water, decreasing its $p H$. As well as, the increase in germination rate and the seed capacity of cucumber seeds before seedling. Statistical analysis showed that our experimental results are highly significant.
\end{abstract}

Keywords: Static magnetic field, Germination, Cucumber seeds.

\section{Introduction}

Many factors limit the development of agriculture. Indeed, the method of treating water by a magnetic field is a technique that has recently been introduced in different fields, including agriculture to alleviate salinity problems of irrigation. The establishment of good crops is one of the main challenges to agricultural production and its importance is recognized by farmers and researchers (Chivasa et al., 1998).

Pang and Deng (2008) have shown that the application of a magnetic field creates changes in the physical and chemical properties of water at the microscopic and macroscopic scale; these results are confirmed by Cai et al., (2009) which indicated that the magnetic treatments have changed some properties of the water such as the surface tension which has been decreased while the viscosity has been increased during the magnetic treatment time. The status of water molecules in a magnetic field leads to changing or decomposing hydrogen bonds between molecules (Aly et al., 2015). The magnetic treatment decreases the solubility of the limestone $(\mathrm{CaCO} 3)$ and promotes its

*Corresponding author's ORCID ID: 0000-0003-3540-4171

DOI: https://doi.org/10.14741/ijmcr.v6i01.10916 precipitation in a bulk solution instead of the reactor walls (Alimi et al., 2006).

The physical and chemical properties of magnetically treated water samples were measured in addition to their bacterial content. In both cases of static and agitation, the amplitude of the magnetic flux is increased as well as the electrical conductivity (EC) (Ben Amor et al., 2017). The researchers observed that magnetized water helps dissolve minerals and acids at a higher rate than nonmagnetized water. Although the equipment used to treat water magnetically is environmentally friendly, competitively priced and does not require energy (Hozyan and Qados, 2010a).

Elaoud et al., (2016) showed the effect of magnetic treatment on the water quality and yield of the melon crop, which showed a $39 \%$ increase in yield compared to the control (raw water).

Recently, the effects of magnetized water have been focused on living systems, particularly for seed germination and development (Shabrangi and Majd, 2009). Although, the first study was started long ago by Savostin (1930) who had shown a $100 \%$ increase in the rate of seedling elongation under the influence of the magnetic field, the results indicate that the magnetic field was widely used seed pretreatment to increase vigor, 108 |Int. J. of Multidisciplinary and Current research, Vol.6 (Jan/Feb2018) 
seedling growth, and yields (Ijaz et al., 2015, lqbal et al., 2012, Magdalena et al., 2015).

The treatment of water by a static magnetic field has shown positive effects on the plant by stimulating its growth and improving its productivity (Taymouria, 2015). Shabrangi and Majd (2009) reported that magnetically treated lentil seeds showed better growth and increased faster than untreated controls.

The increase in the vigor of seeds treated by a magnetic field, the growth of seedlings from these seeds and yields is due to the increase in the absorption and assimilation rate of nutrients (Kavi, 1983) and the improvement of photosynthetic activities and the increase of photosynthetic pigments (Lebedev and Litvinenko, 1977), this is confirmed by Belyavskaya, 2001, Eşitken et al., 2004 and sayed, 2014 which indicated that irrigation of the plant at seeds with magnetic water showed a significant increase in chloroplast pigments (chlorophyll a, chlorophyll b and carotenoids), photosynthetic activity compared to those irrigated by raw water. Significant increases in pigment fractions were recorded in chickpea plants irrigated with magnetized water compared to the control treatment (Nasher, 2008). Thus, respiration and photosynthesis of the seed increase, water assimilation becomes faster, which ultimately improves seed viability (Putincev and Platonova, 1997). The strength of the magnetic field could have stimulating effects on plant metabolism, such as photosynthesis and hormonal and enzymatic balances (estiken et al., 2014). In addition, exposure to the magnetic field also improves ion concentration, free radicals, and physical changes that promote better seed germination (Haq, 2012).

Therefore, pretreatment of seeds by magnetic field provides a safe, inexpensive and harmless option (Podlesny et al., 2004). Few researchers have also studied the comparison of the direct and indirect effects of magnetic treatment on seeds. The behavior of seeds passed through a magnetic device (direct effect) is different from that of normal seeds sown with the magnetic irrigation of water (indirect effect). Researchers have reported that the direct and indirect method has a positive effect on seed germination (Alexander and Doijode, 1995, Carbonell, 2000) and also on plants such as onions (Dagoberto, 2002), wheat (Harichand et al., 2002), maize (Florez et al., 2007), rice (Alexander and Doijode, 1995), sunflower (Vashisth and Nagarajan 2010) and tomato (Moon and Chung, 2000). In this context, our subject arises to study the variation of the physical properties of the magnetized water like the $\mathrm{pH}$ and its effect on the germination of the seeds of the family of cucurbitaceae (cucumber).

\section{Materials and methods}

Studies and monitoring of the magnetization of water and germination were carried out between the Laboratory of Environmental Sciences and Technologies, Higher
Institute of Environmental Sciences and Technologies Borj Cedria and the Sectoral High School of Agricultural Training in Citrus and Vines Bouchrik- Tunisia

Germination tests were performed to study the effect of static magnetic fields $(0.29 \mathrm{~T}$ and $0.5 \mathrm{~T}$ ) on germination of cucumber seeds with well water $(2.5 \mathrm{~g} / \mathrm{I})$. The test was carried out in an ambient temperature of $17 \pm 2 \circ \mathrm{C}$. Seeds of uniform size and shape without visible defects are used.

Two tests are carried out with two magnetic devices of intensity A1 = 2900 Gauss and A2 = 5000 Gauss.

\section{pH measure}

The experimental setup is a complete random block with three repetitions. In each block contains three tests. In this work, the magnetic devices (M1 = 2900 Gauss and $\mathrm{M} 2=5000$ Gauss) are mounted on an experimental system for 62 hours to obtain water magnetized by a static magnetic field (Fig.1)

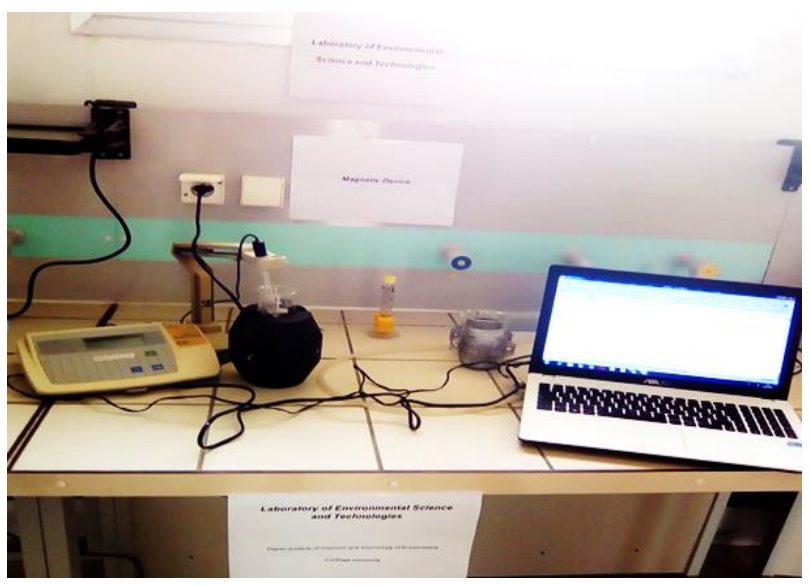

Fig.1 Magnetic device

\section{Seed germination}

Six Petri dishes used for each test (three treated with magnetized water and three with sample water), each containing ten cucumber seeds for each test during the germination period which was estimated at 18 days (Fig.2). We note magnetized water (M) and nonmagnetized water (NM). The measurements are related to the germination capacity and the length of the shoots and rootlets for each seed.

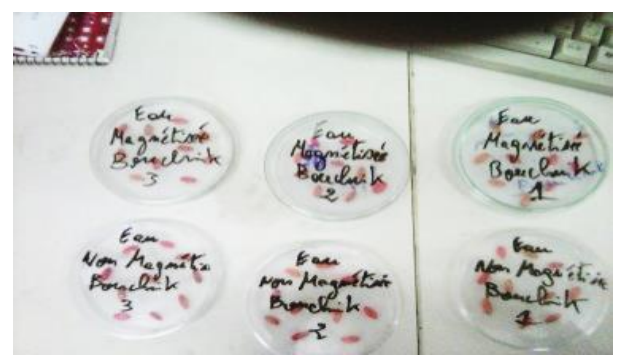

Fig.2 Magnetic treatment on seed germination 
Seed emergence counts were made with a progression of visible radicals through the integument. Data on germination rate, days taken up to $50 \%$ emergence and average germination time were recorded up to 12 days. The evolution of the germination rate is faster for seeds treated with magnetized water compared to untreated seeds. The longest roots and shoots were recorded with water treated seeds and the shortest stem and root were observed in untreated seeds. The main objective of this study was to evaluate the effects of magnetic treatment on seed germination.

\section{Results and discussions}

\section{*Static magnetic field effect on the $\mathrm{pH}$ of water}

The test has been redone several times; the last results have been illustrated in Fig. 3

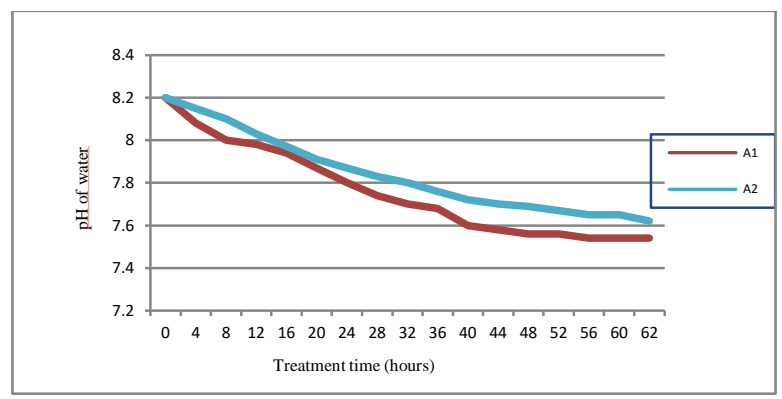

Fig. $3 \mathrm{pH}$ variation of treated water with a static magnetic field $\mathrm{A} 1=0.5$ Tesla, $\mathrm{A} 2=0.29$ Tesla

Experimental evidence shows that when normal water is exposed to the magnetic field, some of its easily measurable properties are changed, such as conductivity, surface tension, salt solubility, refractive index, and $\mathrm{pH}$ (Smakina, 1981).

It is noted that the water subjected to a magnetic field in the device showed a decrease in $\mathrm{pH}$ ranging from 8.2 to 7.62 for the intensity of $0.5 \mathrm{~T}$ and 7.54 for the intensity of $0.29 \mathrm{~T}$ (Fig.3).

\section{*Germination test}

The results show that the percentage of germination was higher for seeds treated with magnetized water. The beginning of germination occurred earlier (Fig.4).

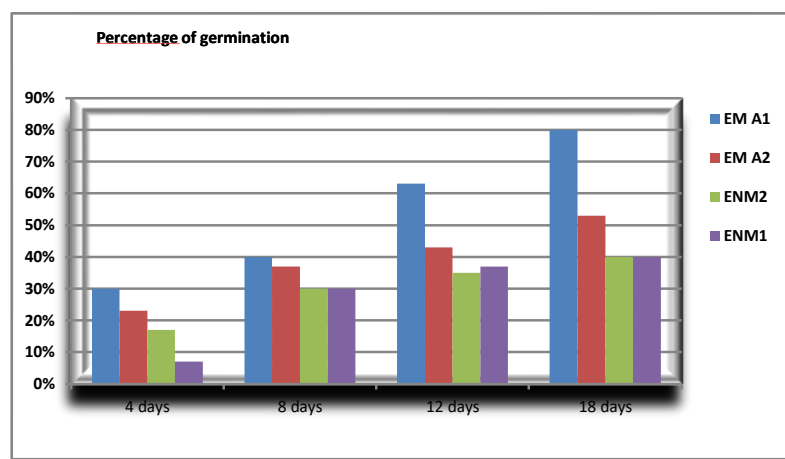

Fig.4 Germination rate of cucumber seeds treated with magnetized water A:0.5 Tesla, A2: 0.29 Tesla and control (ENM1, ENM2)
The germination percentage of the control seeds is always lower than that corresponding to the magnetic treatments applied. Magnetic processing modifies the properties of water; magnetized water is the best treatment for improving the harmful effects of water stress (Tian et al., 1989, Selim and El Nady, 2011).

The germination rate varies from $30 \%$ after 4 days priming of the seeds in magnetically treated water up to $80 \%$ with an intensity $A 1=0.5 T$ while it varies from $23 \%$ to $53 \%$ for A2: $0.29 \mathrm{~T}$ while this rate is $7 \%$ to $40 \%$ for seed treated with raw water (Fig.5)

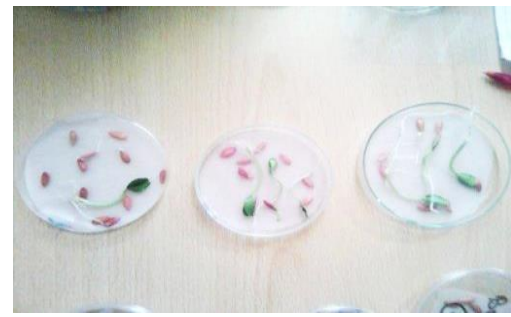

Fig.5 Germination rate of cucumber seeds treated with magnetized water

\section{*Germination rate}

The germination rate varies from $30 \%$ after 4 days priming of the seeds in magnetically treated water up to $80 \%$ with an intensity $\mathrm{A} 1=0.5 \mathrm{~T}$ while it varies from $23 \%$ to $53 \%$ for A2: 0.29 T while this rate is $7 \%$ to $40 \%$ for seed treated with raw water (Fig.6).

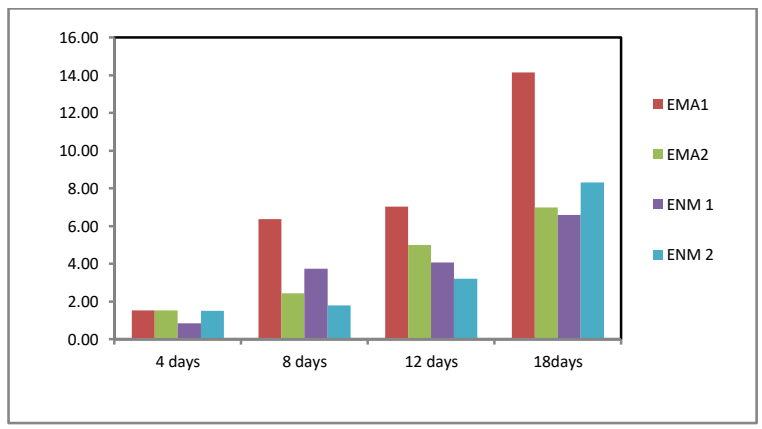

Fig. 6 Evolution of germination rate of seeds treated by a magnetic field (A1: 0.5 T, A2: 0.29 T) and control

The response of the seeds to the static magnetic field depends on the intensity of the magnetic field, the period of exposure, species and seed varieties (Fig.7).

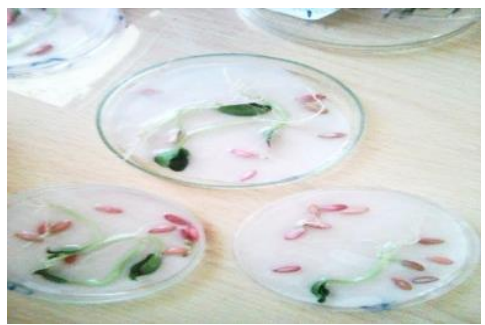

Fig.7 Effect of magnetized water on length and growth of sprouted seeds

110 | Int. J. of Multidisciplinary and Current research, Vol.6 (Jan/Feb 2018) 
Static magnetic fields have been reported to increase shoot and seed length (Aladjadjiyan, 2002). Figure 7 shows that the application of a magnetic field increases the germination rate and the percentage of treated sprouts compared to untreated plants in accordance with (florez 2012)

Magnetic and electromagnetic treatments are used in agriculture as a non-invasive technique to improve seed germination and increase yields. Previous reports summarize the beneficial effects observed on magnetically treated seeds under different conditions, which depend on the specific magnetic treatment applied, such as exposure time, stationary or alternating magnetic field strength, frequency, etc. Poinapen et al., (2013) assessed the role and contribution of different environmental factors to tomato seed germination and found that seed orientation and static magnetic forces influenced seed imbibition more than relative humidity and moisture, exposure time. Magnetic fields favored germination rates of bean and wheat seeds and, in addition, treated plants grew faster than control plants (Cakmak et al. 2010). The influence of magnetic field treatment on two pea varieties was favorable for seed emergence, growth, development, and final yield (Podlesny et al. 2005). In addition, electromagnetic stimulation of amaranth seeds has resulted in an increase in essential fatty acids and a decrease in most saturated fatty acids (Sujak and Dziwulska-Hunek, 2010). Magnetic treatment improved early germination and growth characteristics of chickpea (Vashisth and Nagarajan, 2008), beans and wheat (Cakmak et al., 2010), soybeans (Shine et al., 2011) and corn (Shine and Guruprasad, 2012).

Similar studies on rice and onion have shown that magnetic pretreatment improves the germination and vigor of seedlings that are not very viable (Alexender, 1995). Magnetic field pretreatment also had a positive effect on cucumber, such as stimulation of seedling growth and development (yinan, 2005).

Some previous studies have confirmed that pretreatment of seeds by a magnetic field can improve the inhibition of other stress in plants. This magnetic field protects plants against drought and heat stress (Ruzic and Jerman, 2002, Selim and El-Nady, 2011). Exposure to a static magnetic field attenuates the adverse effects of salinity on seed germination and early growth of chickpea seedlings (Thomas et al., 2013) and enhances the growth of organogenesis, biomass and yield of plants grown under salt stress (Radhakrishnan and Kumari, 2013; Baghel et al., 2016; Rathod and Anand, 2016) suggest that the use of this static magnetic field may be useful in the relief of abiotic stress in vitro and in field conditions. De Souza et al. (2006) reported a positive effect of magnetic field pretreatments of tomato seeds on root length and dry weight. The best growth of seedlings due to magnetic treatments has been attributed to the increased efficiency of metabolic activity.
An increased rate of germination of grain seeds exposed to the magnetic field has been obtained; a higher content of albumin, gluten and starch in wheat grains exposed to magnetic fields has been obtained (Pietruszweski, 1996).

An optimal external electromagnetic field can influence the rate and percentage of germination (Florez et al., 2004). Magnetic field strength and exposure time are among the most significant factors influencing seed germination, emergence rate and yield seeds. Magnetic treatment can accelerate the emergence of the plant at 2 3 days, compared to control plants. El-Yazied et al. (2011) and Aladjadjiyan (2002) showed that magnetic field dose and duration of exposure can affect the germination characteristics of different seeds, including tomato and broad variety. In agreement with these results, Souza et al. (2006) concluded that the best germination rate of tomato seeds is obtained with a microscopic force of 0.1 Tesla with an exposure time of 10 minute. Several studies have shown that the strength of magnetic field has significant effects on germination percentage by reducing water salinity (Selim, 2008). Rochalska (2001) found that magnetic field treatment improved the germination process under stress conditions. El-Yazied et al (2011) demonstrated that the time of exposure to magnetic field can significantly influence the percentage of germination by modulating the salinity of the water. They also concluded that increasing magnetic field strength significantly reduces the number of days required for germination compared to untreated seeds (El-yazid, 2011). In agreement with these results, Pietruszewski, (1996) revealed that Magnetic treatement wheat seeds can accelerate germination compared to untreated samples. In addition, the time of exposure to magnetic field plays an important role in the germination rate when different periods of exposure result in a different minimum time required for germination. However, Florez et al. (2007) showed that the time required for germination in each magnetic treatment of different forces and periods is less than the values recorded by the control.

Increasing the salinity level increases the time required for germination. Some studies have reported that increasing salt concentration delays the germination of tomato seeds (Martinez et al., 2009).

In previous studies, we found that the magnetic treatment of $0.125 \mathrm{~T}$ and $0.250 \mathrm{~T}$ produces $\mathrm{a}$ biostimulation on the initial growth stages and an increase in the germination rate of several seeds such as rice, wheat and barley (Martinez et al, 2000, Martinez et al., 2002 and Florez et al., 2004). This static field positively influenced plant growth by increasing the length of shoots and maize roots (Florez et al., 2007). The germination rate and early growth characteristics of soybean and corn seeds have been increased under static magnetic treatment, this may be due to an increase in the rate of water absorption and higher activities of the enzyme $\alpha$-amylase and protease (Shine et al., 2011, Shine and Guruprasad, 2012). Static magnetic treatment of corn 
seeds has improved growth and photosynthesis under soil moisture stress (Anand et al., 2012). Static magnetic field exposure mitigates the adverse effects of salinity on seed germination and early growth of chickpea seeds (Thomas et al. 2013). Static magnetic treatment has caused a significant increase in the height, leaf area and dry weight of plants subjected to salt stress (Rathod and Anand, 2016, Baghel et al., 2016, Kataria et al., 2017). In addition, a positive response in grasses seeds was observed; Magnetic field exposure allowed earlier germination, increased seed germination, and increased root length in Festuca arundinacea Schreb. and the seeds of Lolium perenne L. (Carbonnel, 2008). Recently, magnetic field exposure of 0.125 Tesla and 0.250 Tesla to pea and lentil seeds has been investigated; growth parameters such as total weight, stem weight, total length and stem length are measured at days 7 and 14, and these parameters are increased; therefore, plants from magnetized seeds became larger and heavier than plants from the control seeds. Increased root development has also been observed (Martinez, 2009). The same results are obtained by Fischer (2004) who showed that sunflower seeds exposed to magnetic fields showed significant increases in total fresh weight, fresh shoot weight and fresh root weight. Similar results for treated wheat that showed marginally higher weights, but significantly higher fresh and dry root weights, total fresh weights, and higher germination rates.

Aladjadjyan, (2002) showed increased sprouting and shoot development when maize seeds were exposed to a magnetic field of 0.150 Tesla intensity for 10 to 30 minutes; the same results with tobacco seeds were obtained (Aladjadjyan, 2003). Yano et al., (2001) found that the induction of primary radicular curvature in radish seeds in a static magnetic field was observed. Also, a positive effect of magnetic treatment on germination and emergence of bean cultivars has been confirmed; the emergence of plants from magnetized seeds was 2 to 3 days earlier than that of control, the yield being increased with a higher number of pods per plant (Podlesny et al., 2004). Corn (Zea mays L.), chickpea (Cicer arietinum L.) and sunflower (Helianthus annus L.) seeds were exposed to different magnetic fields and sown in greenhouses. The maximum improvement in seedling growth and root characteristics was observed under different combinations of magnetic field and duration of exposure. Of the three species, it was noted that protein-rich chickpeas required less magnetic energy, followed by starch-rich corn seeds and lipid-rich sunflower seeds to achieve the improvement required for growth of the chickpeas seedlings. The characteristics of plant roots showed an increase in root length, root surface and root volume.

Same results obtained by Soltani et al., (2006) who pointed out that in a magnetic field, asparagus seeds imbibed and germinated more rapidly. Seed germination percentage and epicotyl and hypocotyl lengths were also significantly higher. In addition, the number of germinated Ocimun basilicum seeds and the length of the radical and primary stem were significantly higher with a static magnetic field.

Plant cultivation under static magnetic water treatment could be an alternative means of crop improvement in future agricultural techniques. Magnetic processing has improved the effect of stress to a certain extent, which can be attributed to maintaining better crop performance and yield. Interaction of magnetized water on seed germination, these results from the seed germination study revealed that magnetized water had a positive impact on the Amaranthaceae family compared to normal water. In the same way, in the case of Amaranthus blitum, germination vigor was started at 36 hours from the incubation period in magnetized treated water compared to normal. Germination parameters such as sprouted seeds and germination times were recorded. The number of sprouts was calculated at different time intervals, 72 and 96 hours.

Recently, Waleed et al. (2013) reported that the magnetic field of 0.5 Tesla resulted in an increase in root length and weight. A remarkable improvement induced by the magnetic treatment was consistent with the results of other studies on onion (Dagoberto et al., 2002), corn (Florez and Doijode, 1995), sunflower (Vashisth and Nagarajan, 2010) and tomato (Moon and Chung, 2000), magnetized water has increased the yield and yield characteristics of all crops (Hozayn et al., 2015).

Many authors have found that magnetic field increase seed germination rates and increase seedling growth rate, activated protein synthesis, and increased root growth (Carbonell et al., 2000, Martíne et al. 2009, Florez et al., 2007). Many studies have found a higher percentage of germination and greater plant growth (Kavi, 1983, Phirke et al. ., 1996a, Hilal and Hilal, 2000, Moon and Chung, 2000). Samy (1989) observed earlier flowering and increased yield of cauliflower (Brassica oleraceae) resulting in exposure to a static magnetic field for 8 hours. De Souza et al. (2006) found that treatment with a static magnetic field with induction of $0.08,0.1$ and $0.17 \mathrm{~T}$ increased the germination rate of tomato seeds (Solanum lycopersicum L.) by 5 to 25\%. Phirke et al. (1996a, b) reported more pronounced effects on soybean and cotton from Indian trees (Gossypium arboreum (L.) and wheat (Triticum aestivum L.). Moon and Chung (2000) found greater effects on tomato germination using alternative electromagnetic fields, and the same results were obtained by Alexander and Doijode (1995) who noted that low viability onions (Allium cepa L.) and rice seeds exposed to a weak electromagnetic field for 12 hours in magnetically treated water increased germination rates and seedling root and shoot length. Celestino et al. (2000) who reported increased germination and growth of Quercus suber exposed to high strength magnetic fields. The same results improved by Harichand et al. (2002) that magnetic field strength of 0.10 Tesla for 40 hours increased plant height, seed weight per head, and wheat yield. Aladjadjiyan (2002) 
stated that the magnetic field stimulated the development of maize shoots and led to an increase in germination rate and survival, fresh weight and shoot length. The same applies to the growth of bean sprouts (Vicia faba L.) exposed to magnetic fields of 0.15 Tesla for 30, 50 and $70 \mathrm{~min}$. Their results showed that magnetic field application improved seed performance in terms of germination rate, seedling length, and fresh and dry weight of seedlings compared to unexposed controls.

\section{Statistical analysis}

\section{*Germination test}

We observe the high significance of results of germination test with a regression $\mathrm{R}(0.82)$ (Table 1 ).

To test the significance of the regression analysis of variance is performed according to the standard procedure.

MLR analysis is a well-known approach which identifies the relationship between a set of dependent and independent variables using statistical methods. The relations between the dependent variable and number of independent variables are in the form:

$Y i=a 0+a 1 X 1+a 2 X 2+a 3 X 3+\ldots .+a k X k+\varepsilon i$

Where, for a set of " $\mathrm{i}$ " successive observations, the predicted variable $\mathrm{Y}$ is a linear combination of an offset
" $\mathrm{a} 0$ ", a set of " $\mathrm{k}$ " predictor variables " $\mathrm{X}$ " with matching "a" coefficients, and a residual error $\varepsilon$. The " $a$ " values are commonly derived via the procedure of ordinary least squares. When the regression equation is used in predictive mode, $\varepsilon$ (the difference between actual and predicted values) is omitted because its expected value is zero.

It should be noted that in our model " $Y$ " represents the response value (Yield of production).

While $X$ represents the independent variables [magnetic field intensity $(I)$ and time $(T)$ ].

\section{Statistical modeling leads us to write}

\section{$Y=-5.2 I+0.24 T+0.02$}

In this test, a 95\% level of confidence was chosen. If the calculated $F$ value is greater than the $F$ critical value, there is a real relation between dependent and independent variables. Since the calculated F-value $(F=33,6329163)$ is greater than the critical F-value $(F=1,0876 E-08)$, so the significance is strong. Therefore, it is concluded that the model is valid.

The descriptors and the regression coefficient of this model presented in Table 3 demonstrated that all the parameters properties measures were statistically significant in estimating $\mathrm{Y}$ (Germination number) ( $\mathrm{P}$-value $<0.05)$.

Table 1 Statistical regression of germination test

\begin{tabular}{cc}
\hline \multicolumn{2}{c}{ Statistical regression } \\
\hline Multiple determination coefficient \\
Coefficient of determination $\mathbf{R}^{2}$ & $\mathbf{0 . 8 2}$ \\
Standard Error & 0.67 \\
Observations & 1.26 \\
\hline
\end{tabular}

Table 2 Analysis of variance of germination

\begin{tabular}{cccccc}
\hline & $\begin{array}{c}\text { Degree of } \\
\text { freedom }\end{array}$ & Sum of squares & $\begin{array}{c}\text { Average of } \\
\text { squares }\end{array}$ & F & $\begin{array}{c}\text { Critical value } \\
\text { of } \mathbf{F}\end{array}$ \\
\hline Regression & 2 & 106,501394 & 53,2506969 & 33,6329163 & $1,0876 \mathrm{E}-08$ \\
Residues & 33 & 52,2486062 & 1,5832911 & & \\
Total & 35 & 158,75 & & & \\
\hline
\end{tabular}

Table 3 Analysis of coefficients and probabilities of germination

\begin{tabular}{ccccc}
\hline & Coefficients & Standard Error & Statistical t & Probability \\
\hline Constant & 0,02157768 & 0,48226665 & 0,04474221 & 0,96458244 \\
Variable I & 5,20408766 & 1,11669379 & 4,66026382 & $5,002 \mathrm{E}-05$ \\
Variable T & 0,24038462 & 0,03561829 & 6,74890908 & $1,0837 \mathrm{E}-07$ \\
\hline
\end{tabular}

*Speed of germination

Statistical modeling of speed germination S

$S=-0.627 T+6.457 I-2.789$
In this test, a $95 \%$ level of confidence was chosen. If the calculated $F$ value is greater than the $F$ critical value, there is a real relation between dependent and independent variables. Since the calculated F-value $(F=56,6768588)$ is greater than the critical F-value 


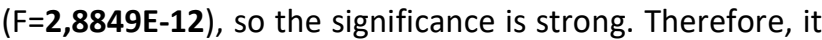
is concluded that the model is valid.

The descriptors and the regression coefficient of this model presented in Table 3 demonstrated that all the parameters properties measures were statistically significant in estimating $\mathrm{S}$ : speed germination- (P-value < 0.05).

Table 4 Statistical regression of speed of germination test

\begin{tabular}{cc}
\hline \multicolumn{2}{c}{ Statistical regression } \\
\hline Multiple determination coefficient \\
Coefficient of determination $\mathrm{R}^{2}$ & $\mathbf{0 . 8 6}$ \\
Standard Error & 0.74 \\
Observations & 2.07 \\
\hline
\end{tabular}

Table 5 Analysis of variance of speed germination

\begin{tabular}{cccccc}
\hline & $\begin{array}{c}\text { Degree of } \\
\text { freedom }\end{array}$ & Sum of squares & $\begin{array}{c}\text { Average of } \\
\text { squares }\end{array}$ & $\mathbf{F}$ & $\begin{array}{c}\text { Critical value } \\
\text { of } \mathbf{F}\end{array}$ \\
\hline Regression & 2 & 487,421799 & 243,710899 & 56,6768588 & $2,8849 \mathrm{E}-12$ \\
Residues & 39 & 167,70028 & 4,30000718 & & \\
Total & 41 & 655,122079 & & & \\
\hline
\end{tabular}

Table 6 Analysis of coefficients and probabilities of speed germination

\begin{tabular}{ccccc}
\hline & Coefficients & Standard Error & Statistical t & Probability \\
\hline Constant & $-2,78915181$ & 0,79382553 & $-3,5135577$ & 0,00113588 \\
Variable T & 0,62727527 & 0,06444091 & 9,73411536 & $5,4583 \mathrm{E}-12$ \\
Variable I & 6,45780679 & 1,64706381 & 3,92079941 & 0,00034676 \\
\hline
\end{tabular}

\section{Conclusion}

The use of static magnetic field affects the physical characteristics by decreasing the $\mathrm{pH}$ of the water.

Also, regardless of the intensity of the device an effect on seed germination is marked. The germination capacity and the germination rate can be improved in the case of treatment with the magnetized device.

For more, germination rate and percentage of germination of control seeds is also below that corresponding to magnetic treatments applied. In summary, stationary magnetic fields could be used as a physical technique to improve the germination.

\section{Acknowledgments}

Our thanks for all the members of the Sectoral High School of Agricultural Training in Citrus and Vines Bouchrik- Tunisia.

\section{References}

[1]. Aladjiyan A. (2002). Study of the influence of magnetic field on some biological characteristics of Zea mais. Journal Central European Agriculture, 3, (2), 89.

[2]. Aladjiyan A., Yillieva T. (2003) Influence of stationary magnetic field on the early stages of development of tobacco seeds (Nicotiana tabacum, L). J. Central European Agriculture 4, (2), 132

[3]. Alexander M.P., Doijode S.D. (1995). Electromagnetic field, a novel tool to increase germination and seedling vigour of conserved onion (Allium cepa, L.) and rice (Oryza sativa, L.) seeds with low viability. Plan Genet. Resources Newsletter, 104, 1.

[4]. Alimi F., Tlili M., Amor M., Gabrielli C., Maurin G. (2006). Influence of Magnetic Field on Calcium Carbonate Precipitation. Desalination, 206: 163- 168

[5]. Aly, M. A., 1Thanaa, M. Ezz, 20sman S. M. and Abdelhamed. A. A. Mazek (2015): Effect of Magnetic Irrigation Water and Some Anti-Salinity Substances on the Growth and Production of Valencia Orange. Middle East Journal of Agriculture Research, Volume : 4 Issue : 01 JanMar.2015, Pages: 88-98.

[6]. Anand, A., Nagarajan, S., Verma, A., Joshi, D., Pathak, P., Bhardwaj, J. (2012). Pre-treatment of seeds with static magnetic field ameliorates soil water stress in seedlings of maize (Zea mays L.). Indian Journal of Biochemistry and Biophysics. 49, 63-70.

[7]. Baghel, L., Kataria, S., Guruprasad, K. N. (2016). Static magnetic field treatment of seeds improves carbon and nitrogen metabolism under salinity stress in soybean. Bioelectromagnetics 37, 455- 470.

[8]. Belyavskaya, N.A. (2001). Ultrastructure and calcium balance in meristem cells of pea roots exposed to extremely low magnetic fields. Advance in Space Resherch. 28, 645-650.

[9]. Ben Amor H., Elaoud A., Ben Salah N., Elmoueddeb K. (2017). Effect of Magnetic Treatment on Surface Tension and Water Evaporation. International Journal of Advance Industrial Engineering, Vol.5, No.3, 119-124.

[10]. Cai R., Yang H., He J., Zhu W. (2009). The Effects of Magnetic Fields on Water Molecular Hydrogen Bonds. Journal of Molecular Structure, 938:15-19. 
[11]. Cakmak, T., Dumlupinar, R., Erdal, S. (2010). Acceleration of germination and early growth of wheat and bean seedlings grown under various magnetic field and osmotic conditions. Bioelectromagnetics 31, 120-129.

[12]. Carbonell M. V., Martinez E., Amaya J. M. (2000) Stimulation of germination in rice (Oryza sativa, L.) by a static magnetic field. Electro-and Magnetobiology, 19, (1) 12.

[13]. Carbonell M. V., Martinez E., Florez M., Maqueda R. Lopezpintor A., Amaya J.M. (2008). Magnetic field treatments improve germination and seedling growth in Festuca arundinacea Schreb. and Lolium perenne L. Seed Science and Technology, 36, 31

[14]. Celestino, C., Picazo, M.L., Toribio, M., (2000). Influence of chronic exposure to an electromagnetic field on germination and early growth of Quercus suber seeds: preliminary Study Journal Electromagn Biol. 19, 121-128.

[15]. Chivasa W., Harris D., Chiduza C., Nyamudeza P., Mashingaidze A. B., (1998). Agronomic practices, major crops and farmers' perceptions of the importance of good stand establishment in Musikavanhu Communal Area, Zimbabwe. The Journal of Applied Science in Southern Africa 4, 9-25.

[16]. Dagoberto, G.F., Angel, D.S.T. and Lilita, S.P. (2002). Effect of magnetic treatment of onion (Allium cepa) seeds on the germination and growth of seedlings. Alimentaria. 39: 181186.

[17]. De Souza A., Garcia D., Sueiro L., Gilbert F., Licea L., Porras E. (2006). Pre sowing magnetic treatment of tomato seeds increase the growth and yield of plants. Bioelectromagnetic Biol Med 27:173-184.

[18]. Elaoud A., Turki N., Ben Amor H., Jalel R., and Ben Salah N. (2016). Influence of the Magnetic Device on Water Quality and Production of Melon. International Journal of Current Engineering and Technology, Vol.6, No.6 : 2256-2260.

[19]. El Sayed H., El Sayed A. (2014). Impact of Magnetic Water Irrigation for Improve the Growth, Chemical Composition and Yield Production of Broad Bean (Vicia faba L.) Plant American Journal of Experimental Agriculture. 4: 476-496

[20]. Esitken, A., Turan, M. (2004). Alternating magnetic field effects on yield and plant nutrient element composition of strawberry (Fragaria $\mathrm{x}$ ananassa cv. Camarosa). Acta Agriculturae Scandinavica, Soil and Plant Science. 54, 135139

[21]. Florez M., Carbonell M. V., Martinez E. (2004). Early sprouting and first stages of growth of rice seeds exposed to a magnetic field. Electro-and Magnetobiology 19, (3), 271.

[22]. Flórez M., Carbonell M.V., Martínez E. (2007). Exposure of maize seeds to stationary magnetic field: effects on germination and early growth. Environmental and Experimental Botany 59, 68.

[23]. Flórez M., Martínez E., Carbonell M V. (2012). Effect of Magnetic Field Treatment on Germination of Medicinal Plants Salvia officinalis L. and Calendula officinalis L. Polish Journal Environmental Studies, 57-63.

[24]. Harichand, K.S., Narula, V., Raj, D. and Singh, G. (2002). Effect of magnetic fields on germination, vigour and seed yield of wheat. Seed Resherch. 30: 289-293.

[25]. Haq, Z., Jamil, Y., Irum, S., Randhawa, M.A., Iqbal, M. and Amin, N. (2012). Enhancement in the germination, seedling growth and yield of radish (Raphanus sativus) using seed pre-sowing magnetic field treatment. Polish Journal Environmental Studies. 21: 369-374.
[26]. Hilal, M.H. and Hillal, M.M (2000a): Application of magnetic technologies in desert agriculture .1-Seed germination and seedling emergence of some crop in a saline calcareous soil. Egyptian Journal of Soil Science. 40:(3), 413-421. 6.

[27]. Hilal, M. H. and Hillal, M. M. (2000b): Application of magnetic technologies in desert agriculture. II-Effect of magnetic treatments of irrigation water on water on salt distribution in olive and citrus field and induced changes of ionic balance in soil and plant. Egyptian journal of soil science, 40:(3),423-435

[28]. Hozayn M., Qados A., (2010a). Irrigation With Magnetized Water Enhances Growth, Chemical Constituent and Yield of Chickpea (Cicerarietinum L.). Agriculture and Biology Journal of North America, 1(4): 671-676. M.

[29]. Hozayn M., Qados A., (2010b). Magnetic Water Technology, a Novel Tool to Increase Growth, Yield and Chemical Constituents of Lentil (Lens esculenta) Under Greenhouse Condition. American-Eurasian J. Agric and Environ. Sci., 7(4): 457-462.

[30]. Hozayn M., El-Shahawy T. A., Abd El-Monem A. A., El-Saady A. A., Darwish M. A. (2015). Allelopathic effect of Casuarina equisetifolia $\mathrm{L}$. on wheat, associated weeds and nutrient content in the soil. African Journal of Agricultural Research. 10, 1675-1683.

[31].Ijaz, B., Umar, M.F., Jatoi, S.A. and Siddiqui S.U. (2015) Effect of magnetically induced structural changes in water and cotton seed on germination behavior. Int. J. Biosci. 7(4): 78-86.

[32]. Iqbal, M., Muhammad, D., Haq, Z., Jamil, Y. and Ahmad, M.R. (2012). Effect of pre-sowing magnetic field treatment to garden pea (Pisum sativum L.) seed on germination and seedling growth. Pak. J. Bot. 44(6): 1851-1856.

[33]. Kavi P.S. (1983). The effect of non homogenous gradient magnetic field susceptibility values in situ ragi seed materiel. Mysore Journal of Agricultural Sciences 17.12-123

[34]. Kataria, S., Baghel, B., Guruprasad K.N. (2017). Pretreatment of seeds with static magnetic field improves germination and early growth characteristics under salt stress in maize and soybean. Biocatalysis and Agricultural Biotechnology. 10, 83-90.

[35]. Lebedev, I.S. and Litvinenko, L.T. (1977). After effect of a permanent magnetic field on photochemical activity of chloroplast. Soviet Plant Physiology. 24: 394-395.

[36]. Magdalena, M.Z., Krzysztof, K., Stanisław, P. and Mariusz, G. (2015). Stimulation with a 130-mT magnetic field improves growth and biochemical parameters in lupin (Lupinus angustifolius L.). Turkish Journal of Biology. 40: 699-705.

[37]. Martinez E., Carbonell M. V., Amaya J.M. (2000) Stimulation on the initial stages on growth of barley (Hordeumvulgare, L.) by $125 \mathrm{mT}$ stationary magnetic field. Electro- and magneticobiology, 19, (3), 271.

[38]. Martinez E., Carbonell M. V., Florez M. (2002). Magnetic biostimulation of initial growth stages of wheat (Triticum aestivum, L.). Electromagnetobiology and Medicine, 21, (1), 43.

[39]. Martinez E., Florez M., Carbonell M.V., Amaya J.M. (2009). Pea (Pisum sativum, L.) and Lentil (Lens culinaris, Medik) Growth Stimulation Due to Exposure to $125 \mathrm{mT}$ and $250 \mathrm{mT}$ Stationary Fields. Pol. Journal Environment Studies, 18, (4) 657.

[40].Moon, J.D. and Chung, H.S. (2000). Acceleration of germination of tomato seed by applying $A C$ electric and magnetic fields. Journal of Electrostatics. 48: 103-114. 
[41].Nasher, S.H. (2008). The Effect of magnetic water on growth of chickpea seeds. Chemical Engineering \& Technology. 26(9):4 pages

[42].Pang X. F., Deng B. (2008). The Change of Macroscopic Features and Microscopic Structures of Water Under Influence of Magnetic Field. Physica B 403: 3571- 3577.

[43]. Pietruszewski, S. (1993). Effect of magnetic seed treatment on yields of wheat. Seed Science and Technology, 21, 621626.

[44]. Pietruszweski S. (1996). Effects of magnetic biostimulation of wheat seeds on germination, yield and proteins. Int Agrophysics 10, (1), 51.

[45]. Podlesni J., Pietruszewski S., Podlesna A. (2004). Efficiency of the magnetic treatment of broad bean seeds cultivated under experimental plot conditions. International Agrophysics, 18, (1), 65.

[46]. Phirke, P.S., Patil, M.N., Umbarkar, S.P., Dudhe, Y.H. (1996) The application of magnetic treatment to seeds: methods and responses, Seed Sci. Technol. 24, 365-373.

[47]. Putincev, A.F. and Platonova, N.A. 1997. Treatment of seed in electromagnetic field (in Russian). Agriculture. 4: 45. 24.

[48]. Poinapen, D., Brown, D.C.W., Beeharry, G.K. (2013). Seed orientation and magnetic field strength have more influence on tomato seed performance than relative humidity and duration of exposure to non uniform static magnetic fields. Journal of Plant Physiol. 170, 1251-1258.

[49]. Radhakrishnan, R., Kumari, B.D.R. (2013). Protective role of pulsed magnetic field against salt stress effects in soybean organ culture. Plant Biosystems. 147, 135-140.

[50]. Rathod, G.R., Anand, A. (2016). Effect of seed magnetopriming on growth, yield and $\mathrm{Na} / \mathrm{K}$ ratio in wheat (Triticum aestivum L.) under salt stress. Indian J. Plant Physiol. 21 15-22.

[51]. Ružič R., Jerman I. (2002). Weak magnetic field decreases heat stress in cress seedlings. Electromagnetic Biology and Medicine 21(1): 43-53.

[52].Samy, C.G. (1989). Magnetic seed treatment. Influence on flowering, siliqua and seed characters of cauliflower. Orissa Journal of Horticulture. 26, 68-69.

[53]. Savostin, P.W. (1930). Magnetic growth relations in plants. Planta. 12: 327.

[54].Selim A.F.H., El-Nady M.F. (2011). Physio-anatomical responses of drought stressed tomato plants to magnetic field. Acta Astr. 69, 387-396.

[55]. Shabrangi, A. and Majd, A. (2009). Effect of magnetic fields on growth and antioxidant systems in agricultural plants. Prog. Electromagnetic. Res. Symposium, Proceedings, Beijing, China, pp.1142-1147.

[56].Shine, M.B., Guruprasad, K.N., Anand A. (2011). Enhancement of germination, growth, and photosynthesis in soybean by pretreatment of seeds with magnetic field. Bioelectromagnetics $32,474-484$
[57]. Shine, M.B., Guruprasad, K.N. (2012). Impact of pre-sowing magnetic field exposure of seeds to stationary magnetic field on growth, reactive oxygen species and photosynthesis of maize under field conditions. Acta Physiologia Plant. 34, 255-265.

[58].Smikhina, L.P. (1981). Change in the refractive index of water on magnetic treatment. Colloid Journal. 2, 401-404.

[59].Soltani F., Kashi F., Arghavani M. (2006). Effect of magnetic field on Ocimun basilicum seed germination and seedling growth. International Symposium on the Labiatae. ISHS Acta Horticulturae 723, 279

[60].Sujak, A., Dziwulska-Hunek, A. (2010). Minerals and fatty acids of amaranth seeds subjected to pre-sowing electromagnetically stimulation. International Agrophys. 24, 375-379.

[61]. Taimourya H., Bourarach E.H., ElHarif A., Hassanain N. Masmoudi L., Baamal L., Oussible M. (2015). Évaluation de la productivité du chou pommé (Brassica oleracea), sous l'effet de l'irrigation avec une eau traitée magnétiquement, dans la région de Casablanca (Maroc). Rev. Mar. Sci. Agron. Vét. 3 (2):27-36.

[62]. Thomas, S, Anand, A., Chinnusamy, V., Dahuja, A., Basu, S. (2013). Magnetopriming circumvents the effect of salinity stress on germination in chickpea seeds. Acta Physiol. Plant. 35, $3401-3411$

[63].Tian, W.X., Luang, Y.L., Mei, Z.P. (1989). Effect of magnetic water on seeds germination: seedling germination growth and grain yield of rice. Journal of Jilin Agricultura University. 11,107-108.

[64]. Vashisth A., Nagarajan S. (2008). Effect of magnetic field on performance of diverse crop species. Indian Journal of Agricultural Sciences, 78, 708.

[65]. Vashisth A., Nagarajan S. (2008). Exposure of seeds to static magnetic field enhances germination and early growth characteristics in chickpea (Cicer arietinum L.). Bioelectromagnetics, 29, (7), 571.

[66]. Vashisth, A., Nagarajan, S. (2010). Effect on germination and early growth characteristics in

[67]. sunflower (Helianthus annus) seeds exposed to static magnetic field. J. Plant Physiol. 167,

[68].149-156.

[69]. Waleed, A., Jabail, Riyadh, C.H., Abul, H. and Hussein, F. (2013). Effect of magnetic field on seed germination of Triticum aestivum. World Journal Agricultural Sciences. 1(5): 168-171.

[70]. Yano A., Hidaka E., Fujiwara K., limoto M. (2001). Induction of primary root curvature in radish seedlings in a static magnetic field. Biolelectromagnetics, 22, 194.

[71]. Yinan L., Yuan L., Yongquig Y., Chunyang L. (2005). Effect of seed pre-treatment by magnetic field on the sensitivity of cucumber (Cucumis sativus) seedlings to ultraviolet-B radiation. Environmental and Experimental Botany, 54, 286. 